\title{
ASSESSMENT OF ACTIVE SHOULDER ROTATION AFTER TENDON TRANSFER AROUND THE SHOULDER IN CASES OF RESIDUAL BRACHIAL PLEXUS INJURY
}

By

\author{
Abd El-Hakim Abd Allah Massoud, Amro A. Fouaad, Ahmed \\ Mohammed Rashad Donia
}

Hand \& Microsurgery Unit, Department of Orthopaedic Surgery, Faculty of Medicine, AlAzhar University

Corresponding author: Ahmed Mohammed Rashad Donia, Mobile: 01148875651

Email: ahmeddonia5@gmail.com

We hypothesize that tendon transfer around the shoulder in patients with brachial plexus injury improves shoulder function specifically external rotation which may affect shoulder internal rotation.

\begin{abstract}
Background: Active range of motion were analyzed as the outcomes of tendon transfer around the shoulder in children who had internal rotation contracture deformities secondary to obstetric brachial plexus palsy (OBPP) to improve the shoulder external rotation. Regarding to importance of external rotation there was some limitation of internal rotation which can affect patient's daily activities.

Methods: 50 patients with brachial plexus injury who underwent tendon transfer (teres major or latissimus dorsi) with or without anterior shoulder release in two separate incisions. Coracohumeral ligament release and Subscapularis release were done for all patients through anterior incision. A separate second incision in the posterior axillary fold was carried out to perform rerouting of the teres major or latissimus dorsi tendon.

Results: The average active external rotation in abduction increased from $23.5^{\circ}$ preoperatively to $76.4^{\circ}$ postoperatively. The average active external rotation in adduction increased from $9.6^{\circ}$ to $77.5^{\circ}$. The average shoulder abduction increased from $74.5^{\circ}$ to $142.6^{\circ}$. Active internal rotation was analyzed just after operation, 6 month after and one year after. There was limited active IR in adduction from $10^{\circ}$ to $50^{\circ}$ with mean average $28.21^{\circ}$ and improvement gradually with physiotherapy.
\end{abstract}

Conclusions: Anterior shoulder release combined with latissimus dorsi or teres major rerouting significantly improved global shoulder function, but with limitations of active internal rotation which improving significally with physiotherapy.

Keywords: Brachial Plexus Injury - Birth Palsy - Tendon Transfer.

\section{INTRODUCTION}

Infant birth weight and the regional obstetric care are the main causes of incidence of brachial plexus birth palsy (BPBP). An epidemiological study reveals an incidence in USA around $0.15 \%$
(Abid, 2016), whereas incidence in Finland refers to $0.31 \%$ (Poyhia et al., 2010). Furthermore, the risk of injury of the brachial plexus is five times higher in breech delivery and may be bilateral (Chomiak et al., 2014). 
Narakas' categorisation is used according to location and severity of the plexus lesion: Group 1, the upper plexus lesion (C5-6, Erb's palsy), with an incidence of $73 \%$ represents, the prognosis is so good reported 75-95\% improvement. Group 2 comprises patients with C5-6 and C7 (extended Erb's palsy) involvement, the prognosis is poorer than for group 1 patients. Groups 3 and 4, with the lesion of the entire plexus (C5-T1), flail upper limb (Whole extremity), with or without Horner's syndrome with an incidence of $25 \%$, this type having the worst prognosis. Physiotherapy with passive exercises used as initial treatment to prevent joint contractures and strengthen the recovering muscles (Chomiak et al., 2014).

Incomplete recoveries in $\mathrm{C} 5-\mathrm{C} 6$ and C5-C7 palsies lead to soft tissue imbalance (strong internal rotators lead to contracture of the internal rotators (pectoralis major, subscapularis, latissimus dorsi and teres major muscles) and weak external rotators and abductors. Bony changes as (Scapular winging, changes in coracoid process, humeral head flattening and glenoid deformity with possible glenohumeral joint posterior dislocation may be affected and causing increasing shoulder deformity (Shah and Ganjwala, 2018). Active external rotation is crucial for upper-extremity function. Therefore, restoring external rotation in combination with shoulder abduction is generally recommended (Hale et al., 2010 and Chomiak et al., 2014).

In congruent glenohumeral joints, muscle release and transfer are indicated. Latissimus dorsi or teres major tendon transfer to rotator cuff is a common procedure (Aydin et al., 2011). We prefer to transfer these muscles to the lateral side of the proximal humrus to restore active external rotation, together with lengthening the pectoralis major and subscapularis muscles (Julka and Vander Have, 2011). The amount of external rotation increases with increased rotation strength and the amount of abduction increases with greater efficacy of the deltoid muscle. Once the imbalance between Muscle forces of the shoulder joint is restored in the early period, the glenohumeral joint undergoes remodeling (Neumann, 2013).The congruity of the glenohumeral joint is the key for release and transfer even at 4 to 10 years of age (Ozturk et al., 2010).

The aim of this study was to evaluate the active shoulder range of motion abduction, external rotation, internal rotation and effect of limited internal rotation on daily activity, in patients 2 to 13 years of age after latissimus dorsi or teres major tendon transfer to the rotator cuff with Coracohumeral release with or without anterior structure release.

\section{PATIENTS AND METHODS}

This is a prospective retrospecive study involving 50 patients underwent surgical treatment between 2014 and 2018 for loss of external rotation and abduction as well as internal rotation contracture of the shoulder secondary to OBPP. Of these patients, 10 patients were lost follow up and 40 cases with forward follow up, 31 of them had upper lesion (C5-6), 5 had (C5-7) with elbow involvement, and 4 had complete plexus involvement (C5-T1) wrist, and hand were involved. The mean operation age was 4.71 years (range 2 to 13 years). There were 17 males $(42.5 \%)$ 
and 23 females (57.5\%). 22 patients (55\%) had right side involvement and 18 patients $(45 \%)$ had left side involvement.

The patients presented with their parents complaints of being unable to use the involved extremity in their daily activities (to eat, hair brush and drink) due to loss of external rotation and abduction accompanying the internal rotation deformity. By examination there is limited or loss of external rotation and abduction accompanying the internal rotation deformity. Latissimus dorsi, teres major and deltoid muscles were assessed preoperatively. The pre and postoperative range of motion values were measured and their motor functions were evaluated with the Mallet scoring system (Waters and Peljovich, 1999). The mean preoperative active abduction was $74.5^{\circ}$ and the mean active external rotation in abduction was $23.5^{\circ}$ and external rotation in adduction was $9.6^{\circ}$. Tendon transfer was performed in patients with sufficient deltoid muscle strength (M3-M4 according to the British Medical Research Council grading system) (Hoffer et al., 1978).

During preoperative planning, bilateral antero-posterior and or axillary direct radiographs of the shoulder were obtained. To evaluate the glenohumeral joint, magnetic resonance imaging (MRI) was performed in patients who had some shoulder deformity, and computed tomography (CT) was performed in 20 patients who were beyond 4 years of age.

Surgical procedure: Anterior shoulder release was done in 38 patients through deltopectoral incision by coracohumeral ligament release and musculotendinous lengthening of the subscapularis and/or pectoralis major then teres major was transferred in $31(77.5 \%)$ patients and latissimus dorsi in 9 patients $(22.5 \%)$ to the rotator cuff through posterior axillary incision (modification to Hoffer technique (Hoffer et al., 1978). After closing surgical incisions a shoulder spica were used to secure the shoulder in maximum abduction and external rotation, and the elbow in $70^{\circ}$ flexion.

Following its full-day use for 6 to 8 weeks, an exercise program was initiated in the gravity-eliminated position without allowing any antagonist activity 2 weeks after cast removal followed by gentle strengthening exercises and light functional use between weeks 8 and 10 . Stretching exercises were initiated after week 12, and the use of extremity was encouraged in daily activities associated with nocturnal splint. The mean follow-up period was (19.8) months (range 8 to 40 months).

\section{Statistical analysis:}

The data obtained from the patients were statistically evaluated by the paired samples test using the SPSS 15.0 software. 


\section{RESULTS}

At final evaluations, with mean cast duration (1.56) months post-operatively, and mean follow up 19.8 months (8 to 40 ), and night splint was used in 8 patients( 20\%) for minimum 4 months, there was improvement of abduction from $74.5^{\circ}$ to $142.6^{\circ}$ (mean improvement $68.13^{\circ}$ ), highly significant improvement, external rotation in abduction increased from $23.5^{\circ}$ to $76.4^{\circ}$ (mean improvement $\left.52.9^{\circ}\right)$, and improvement of external rotation in adduction from $9.6^{\circ}$ to $77.5^{\circ}$ (mean improvement 67.88 ${ }^{\circ}$ ). Improvements in the degrees of abduction and external rotation showed significant difference $(\mathbf{p}<\mathbf{0 . 0 0 1}$ - Table 1$)$.

Table (1): Comparison between pre-operative and post-operative Abd, ER in Abd and ER in Add

\begin{tabular}{|c|c|c|c|c|c|}
\hline \multicolumn{2}{|c|}{$\begin{array}{ll} & \text { Groups } \\
\text { Variables } & \end{array}$} & $\begin{array}{c}\text { Pre-operative } \\
\quad(\mathrm{N}=40)\end{array}$ & $\begin{array}{c}\text { Post-operative } \\
(\mathrm{N}=40)\end{array}$ & Improvement & P-value \\
\hline \multirow{2}{*}{ Abd } & Mean & 74.5 & 142.6 & 68.13 & \multirow{2}{*}{$<0.001 *$} \\
\hline & \pm SD & 25.01 & 29.1 & 24.77 & \\
\hline \multirow{2}{*}{ ER in Abd } & Mean & 23.5 & 76.4 & 52.90 & \multirow{2}{*}{$<0.001 *$} \\
\hline & \pm SD & 20.7 & 18.5 & 26.62 & \\
\hline \multirow{2}{*}{ ER in Add } & Mean & 9.6 & 77.5 & 67.88 & \multirow{2}{*}{$<0.001 *$} \\
\hline & \pm SD & 11.5 & 14.1 & 14.27 & \\
\hline
\end{tabular}

In this study, we were proposing to follow up patient active internal rotation after one month of cast removal and its effect on patient daily activity, there was no limitation in 12 pts. (30\%), $10^{\circ}$ limitation in one patient $(2.5 \%), 20^{\circ}$ limitation in 10 pts. $(25 \%), 30^{\circ}$ limitation in 11 pts. $(27.5 \%), 40^{\circ}$ limitation in 5 pts.
(12.5\%), and in 1 patient $(2.5 \%)$ there was $50^{\circ}$ limited internal rotation. All patient with limited active internal rotation suffering to use their hand in many things like putting the hand inside there trouser bag, wearing clothes and hygiene (Table 2).

\section{Table (2): Description of limited IR in studied patients}

\begin{tabular}{|c|c|c|c|c|}
\hline Variables & Degree & $\begin{array}{c}\text { Studied patients } \\
(\mathbf{N}=\mathbf{4 0})\end{array}$ & $\begin{array}{c}\text { Statistical } \\
\text { analysis }\end{array}$ & $\begin{array}{c}\text { Studied patients } \\
(\mathbf{N}=\mathbf{4 0})\end{array}$ \\
\hline \multirow{4}{*}{$\begin{array}{c}\text { Limited } \\
\text { IR }\end{array}$} & $\mathbf{( 1 0 )}$ & $1(2.5 \%)$ & Mean & 28.21 \\
\cline { 2 - 5 } & $\mathbf{( 2 0 )}$ & $10(25 \%)$ & \pm SD & 9.05 \\
\cline { 2 - 5 } & $\mathbf{( 3 0 )}$ & $11(27.5 \%)$ & Min & 10 \\
\cline { 2 - 5 } & $\mathbf{( 4 0 )}$ & $5(12.5 \%)$ & Max & 50 \\
\cline { 2 - 5 } & $\mathbf{( 5 0 )}$ & $1(2.5 \%)$ & \multirow{2}{*}{ Range } & $(10-50)$ \\
\hline
\end{tabular}

The mean improvement in abduction was $\left(138.25^{\circ}\right)$ and $\left(147^{\circ}\right)$, and the mean external rotation in abduction improved $\left(76.5^{\circ}\right)$ and $\left(79^{\circ}\right)$, and the mean improvement of external rotation in adduction was $\left(75.75^{\circ}\right)$ and $\left(79.25^{\circ}\right)$ in patients $\leq 4$ years and $>4$ years of age, respectively. Changes in abduction and external rotation were not significant between patients $\leq 4$ years and $>4$ years of age (p>0.05 - Table 3$)$. 
Table (3): Comparison between post-operative data as regard age

\begin{tabular}{|l|c|c|c|c|}
\hline \multicolumn{2}{|c|}{ Age } & $\leq 4$ years & $>$ 4 years & \multirow{2}{*}{ P-value } \\
\hline \multirow{2}{*}{ Variables } & Mean & 138.25 & 147.00 & \multirow{2}{*}{0.34} \\
\cline { 2 - 4 } & $\mathbf{\pm S D}$ & 27.78 & 30.50 & \\
\hline \multirow{2}{*}{ ER in Abd } & Mean & 76.50 & 79.00 & \multirow{2}{*}{0.6} \\
\cline { 2 - 4 } & $\mathbf{\pm S D}$ & 15.90 & 14.10 & \\
\hline \multirow{2}{*}{ IR in Abd } & Mean & 58.00 & 61.00 & \multirow{2}{*}{0.53} \\
\cline { 2 - 4 } & $\mathbf{\pm S D}$ & 14.64 & 15.86 & \\
\hline \multirow{2}{*}{ ER in Add } & Mean & 75.75 & 79.25 & \multirow{2}{*}{0.44} \\
\cline { 2 - 4 } & $\mathbf{\pm S D}$ & 12.06 & 16.08 & \\
\hline \multirow{2}{*}{ IR in Add } & Mean & 69.00 & 72.00 & \multirow{2}{*}{0.53} \\
\cline { 2 - 4 } & $\mathbf{\pm S D}$ & 15.18 & 15.08 & \\
\hline
\end{tabular}

\section{DISCUSSION}

In cases of obstetric brachial plexus sequel, the deformity of the shoulder joint and loss of function are the most important problems. The development of this deformity impedes daily activities required for body care such as moving the hand over the head and shoulder, or behind the head. It has been shown in MRI studies that patients older than three months develop secondary deformities such as biconcavity, glenoid convexity, and humeral head subluxation after five months of obstetrical brachial plexus injuries. Arthroscopy, arthrography and MRI have shown that glenohumeral joint deformity occurs before the age of one year in patients with internal rotation contracture (Ozturk et al., 2010). This results from the impaired muscle balance (the internal rotators, maintaining their strength, and external rotators, loosening their strength (Andrés-Cano et al., 2015)). Initial paralysis or late recovery of the external rotators results in shortening of the dominant subscapularis muscle fibers along with increased stiffness and contracture. The fixed internal rotation position of the shoulder has a negative impact on the anatomic structure and development of the glenohumeral joint (Olofsson et al., 2019). Progression in muscle imbalance results in permanent deformities such as glenoid dysplasia, deformation, humeral head subluxation, and posterior dislocation (Cornwall, 2013).

Glenohumeral joint remodeling and glenoid version improvement were achieved by early tendon transfer and musculotendinous lengthening (Cornwall, 2013 and Abzug \& Kozin, 2014).

Zancolli has a method of muscle rerouting and released the pectoralis major from humeral insertion and sutured it distal to the subscapularis for the treatment of internal rotation contracture. To increase the external rotation, he rotated the latissimus dorsi tendon that was lengthened $10 \mathrm{~cm}$ with Z-plasty, from the lateral to the posterior of the humerus and sutured it again onto itself in full external rotation and $90^{\circ}$ of abduction. As a result, he obtained $45^{\circ}$ active external rotation and $50^{\circ}$ active abduction (Terzis and Kostopoulos, 2010). 
Covey et al separate the tendinous part of the latissimus dorsi, re-routed the distal end of it to the posterior aspect of the humerus, and anastomosed it to the conjoined tendons of the latissimus dorsi and teres major. Of 19 patients, 14 patients had increases of $26^{\circ}$ and $29^{\circ}$ in abduction and external rotation respectively, but five did not benefit from the procedure (Odeh and Odeh, 2015).

For the treatment of internal rotation contracture, Gilbert et al recommended open release for children less than 4 years of age if the congruity of the glenohumeral joint and roundness of the humeral head were preserved, they recommended latissimus dorsi transfer in addition to release of the contracture in children greater than 4 years of age (Ozturk et al., 2010). The most popular salvage surgical procedure around the shoulder is the L'Episcopo procedure and its modifications. The modification by Hoffer et al used in our study includes musculotendinous lengthening of the subscapularis and/or pectoralis major, with coracohumeral ligament release as the first step, and transfer of the teres major or latissimus dorsi tendons to the rotator cuff in order to strengthen the paralyzed external rotators. This results in not only increased active external rotation, but also increased abduction because of increases in the stabilizing effect of the rotator cuff and the efficacy of the deltoid muscle. Hoffer et al reported the mean improvements as $64^{\circ}$ in abduction and $45^{\circ}$ in external rotation in 11 patients (Romeih et al., 2015).

In our study, the mean gain was $68.13^{\circ}$ in abduction, external rotation in abduction was $52.9^{\circ}$ and external rotation in adduction gain $67.88^{\circ}$. There was no significant difference between age <or> 4 years old with respect to abduction gain between the two age groups. In patient with preoperative abduction $>90^{\circ}$, we believe that no additional tendon transfer is necessary as an efficient outcome is already obtained with release of the internal rotators. Surgery between ages 2 to 5 years is the best time to achieve muscle balance and to prevent deformities (Hale et al., 2010). As regarding the surgery time, Ozturk et al. (2010) suggested that the most convenient age range for salvage surgery of soft tissues was 4 to 10 years and Andrés-Cano et al. (2015) concluded that the clinical results were related with the type of paralysis and preoperative shoulder functions, but not with age.

In our series with an average age of 4.71 years (from 2 to 13 years) the severity of bone and joint deformities was minimal. We believe that tendon transfer and release surgery of internal rotators in patients with no or minimal joint contracture and osseous deformity can be performed regardless of age.

In this technique which allows restoration of external rotation as well as global abduction, loss of internal rotation is seen especially in patients who undergo release surgery together with tendon transfer. The degree of this loss can be usually reduced by physical therapy (Ozben et al., 2011).

In our cases, loss of internal rotation presented as decreased the ability to move the hand to the back. The patients complain of some limitation during their daily activities, to wear trousers or put hand in trousers pocket. This loss was 
statistically significant, additional therapy was considered as physiotherapy extrinsic and stretching exercise to transferred muscle. Despite this loss in internal rotation, the quality of life was highly improved in our cases due to significant increases in the ability to move the hand to neck and mouth.

There is no consensus in the literature as to the transfer site and fixation method of the tendon. In the L'Episcopo procedure, the tendon is passed posterior to the lateral of the humerus behind the long head of the conjoined triceps, and fixed with a surgical stapler or screw, or sutured on to the removed periosteal flap (Bertelli, 2011). In the modification of Hoffer et al (Bahm, 2016), the combined tendon is fixed to anterosuperior of the rotator cuff by non-absorbable $2 / 0$ sutures. In a study of 10 patients, Ozturk et al. (2010) fixed the conjoined tendon onto the infraspinatus tendon with a 2/0 Ethibond suture and obtained a mean postoperative abduction of $134.5^{\circ}$ and ER of $70^{\circ}$. As reported by Bertelli (2009), he preferred to fix the conjoined tendon to the greater tubercle by a suture anchor and sutured it to infraspinatus tendon and he reported the increases as $60.3^{\circ}$ in abduction and $58.7^{\circ}$ in ER in 70 patients.

In our patients, gains in abduction and ER were $68.13^{\circ}$ and $52.9^{\circ}$, respectively. Limited IR in patients, which improved significantly with physiotherapy. Bertelli (2011) performed transfer of the lower part of the trapezius muscle to the infraspinatus and Z-plasty lengthening of the subscapular muscle in seven patients who developed recurrent internal rotation contracture following a subscapular release and transfer of the latissimus dorsi, and achieved an external rotation of $54.3^{\circ}$. Strecker et al reported axillary nerve lesions, being temporary in three patients and permanent in one patient, following transfer of the latissimus dorsi and teres major tendons (Ozturk et al., 2010).

In our study, no complications such as axillary nerve injury, infection, painful range of motion, and recurrent internal rotation contracture were encountered, although limited internal rotation in some cases which improved with physiotherapy.

\section{CONCLUSION}

Coracohumeral ligament release and musculotendinous lengthening of the subscapularis and/or pectoralis major with transfer of teres major or latissimus dorsi tendons to the rotator cuff in cases of limited abduction and external rotation secondary to obstetric brachial plexus palsy provides satisfactory degrees of abduction and external rotation, regardless of age, in patients with no or minimal impairment in congruity of glenohumeral joint. Close Follow up active physiotherapy is recommended to improve postoperative internal rotation contracture.

\section{REFERENCES}

1. Abid, A. (2016): Brachial plexus birth palsy: Management during the first year of life. Orthopaedics \& Traumatology: Surgery \& Research, 102(1): S125-S132.

2. Abzug, J. M. and Kozin, S. H. (2014): Evaluation and management of brachial plexus birth palsy. Orthopedic Clinics, 45(2): 225-232.

3. Andrés-Cano, P., Toledo, M. A., Farrington, D. M. and Gil, J. J. (2015): Arthroscopic treatment for internal contracture of the shoulder secondary to brachial plexus birth palsy: report of a case series and review of the literature. European 
Journal of Orthopaedic Surgery \& Traumatology, 25(7): 1121-1129.

4. Aydın, A., Biçer, A., Özkan, T., Mersa, B., Özkan, S. and Yıldırım, Z. H. (2011): Does primary brachial plexus surgery alter palliative tendon transfer surgery outcomes in children with obstetric paralysis? BMC Musculoskeletal Disorders, 12.1: 74-89.

5. Bahm, J. (2016): The surgical strategy to correct the rotational imbalance of the glenohumeral joint after brachial plexus birth injury. Journal of Brachial Plexus and Peripheral Nerve Injury, 11(01): e10-e17.

6. Bertelli, J. A. (2009): Lengthening of subscapularis and transfer of lower trapezius in the correction of recurrent IR contracture following obstetric brachial plexus palsy. JBJS, 91:943-8.

7. Bertelli, J. A. (2011): Upper and lower trapezius muscle transfer to restore shoulder abduction and external rotation in longstanding upper type palsies of the brachial plexus in adults. Microsurgery, 31(4): 263-267.

8. Chomiak, J., Dungl, P., Ošt’ádal, M., Frydrychová, M. and Burian, M. (2014): Muscle transfers in children and adults improve external rotation in cases of obstetrical brachial plexus paralysis: a comparative study. International Orthopaedics, 38(4): 803-810.

9. Cornwall, R. (2013): Glenohumeral joint secondary procedures for obstetrical brachial plexus birth palsy. The Pediatric Upper Extremity, 1-22.

10. Hale H. B., Bae D. S. and Waters P. M. (2010): Current concepts in the management of brachial plexus birth palsy. J. Hand Surg., 35:322-331.

11. Hoffer M. M., Wickenden R. and Roper B. (1978): Brachial plexus birth palsy. Results of tendon transfer to the rotator cuff. JBJS, 60:691-5.

12. Julka, A., and Vander Have, K. L. (2011): Shoulder sequelae of neonatal brachial plexus injuries: orthopedic assessment and management. Journal of Pediatric Rehabilitation Medicine, 4(2): 131-140.
13. Neumann, D. A. (2013): Kinesiology of the musculoskeletal system-e-book: Foundations for Rehabilitation. Elsevier Health Sciences, 2nd ed., Ch. 5, PP. 121-173.

14. Odeh, R. and Odeh, M. (2015): A modified Sever-L'Episcopo procedure for restoration of shoulder joint function in Erb's palsy. International Orthopaedics, 39(2): 309-317.

15. Olofsson, P. N., Chu, A. and McGrath, A. M. (2019): The Pathogenesis of Glenohumeral Deformity and Contracture Formation in Obstetric Brachial Plexus PalsyA Review. Journal of Brachial Plexus and Peripheral Nerve Injury, 14(01): e24-e34.

16. Ozben, H., Atalar, A. C., Bilsel, K. and Demirhan, M. (2011): Transfer of latissmus dorsi and teres major tendons without subscapularis release for the treatment of obstetrical brachial plexus palsy sequela. Journal of Shoulder and Elbow Surgery, 20(8): 1265-1274.

17. Ozturk, K., Bulbul, M., Demir, B. B., Buyukkurt, C. D., Ayanoglu, S. and Esenyel, C. Z. (2010): Reconstruction of shoulder abduction and external rotation with latissimus dorsi and teres major transfer in obstetric brachial plexus palsy. Acta Orthop. Traumatol Turc. , 44(3): 186-193.

18. Poyhia T. H., Lamminen A. E., Peltonen J. I., Kirjavainen M. O. and Neitosvaara Y. (2010): Brachial plexus birth palsy: US screening for GH joint instability. Radiology, 254:253-260.

19. Romeih M. A., Farouk, E. F. and Mostafa, A. A. (2018): Outcome of Tendon Transfer Around Shoulder with Erb's Palsy Internal Rotation Deformity. The Medical Journal of Cairo University, 86: 449-455.

20. Shah, M. and Ganjwala, D. (2018): Current Concept in the Management of Brachial Plexus Birth Palsy, Treatment of Brachial Plexus Injuries, Vicente Vanaclocha and Nieves Sáiz-Sapena, 5(11): 1-16.

21. Terzis, J. K. and Kostopoulos, E. (2010): Our experience with secondary reconstruction of external rotation in obstetrical brachial plexus palsy. Plastic and Reconstructive Surgery, 126(3): 951-963. 
22. Waters P.M. and Peljovich A.E. (1999): Shoulder reconstruction in patients with chronic BPBP. A case control study. Clin. Orthop. Relat. Res., (364):144-52. 


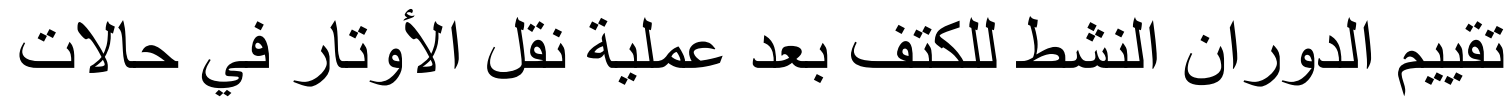

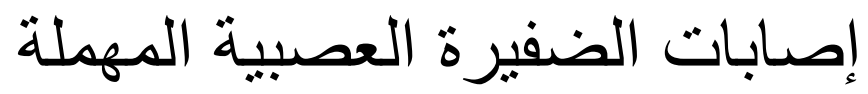

عبدالحكيم عبدالله مسعود، عمرو أحمد فؤاد، أحمد محمد رشاد دنيا قسم جراحة العظام، كلية الطب، جامعة الأزهر

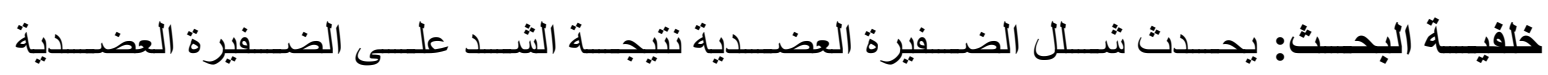

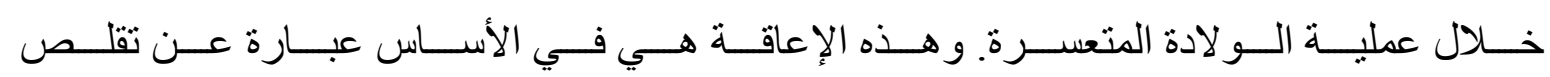

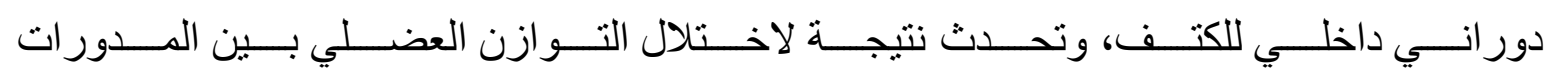

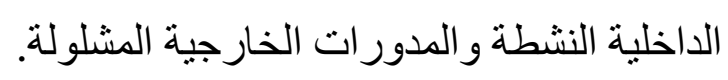

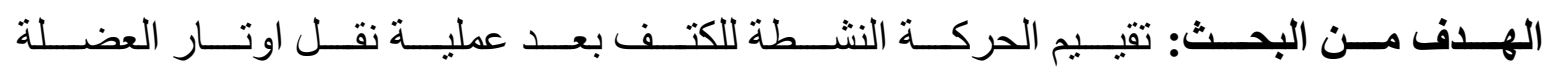

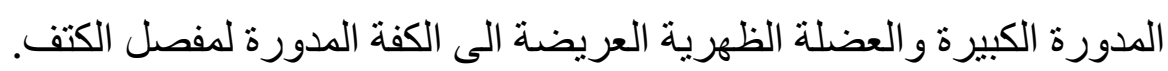

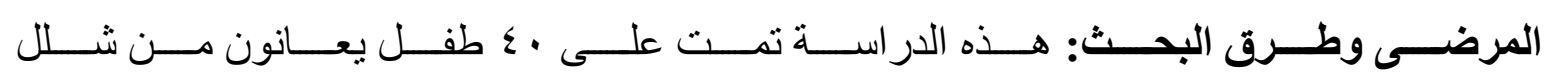

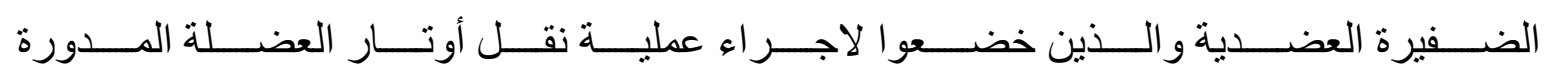

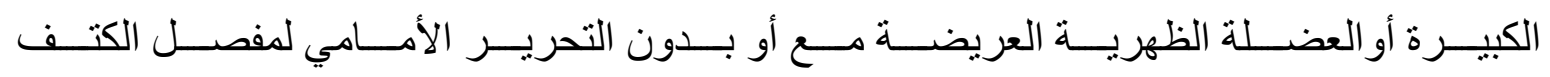

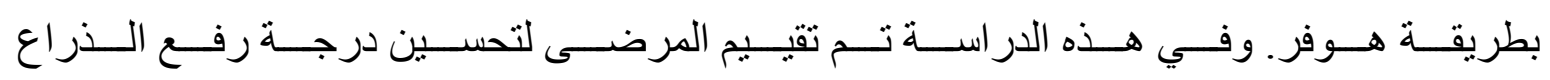
و الدوران الخارجي للكتف بعد 6 أثنهر على الأقل من العملية.

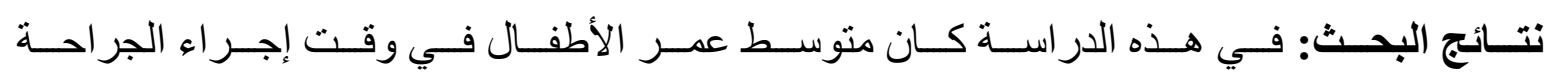

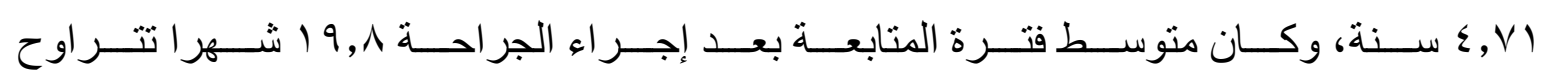

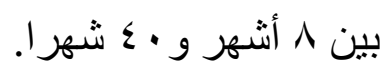

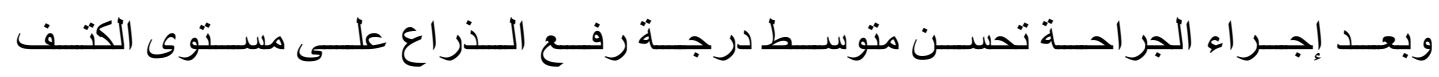

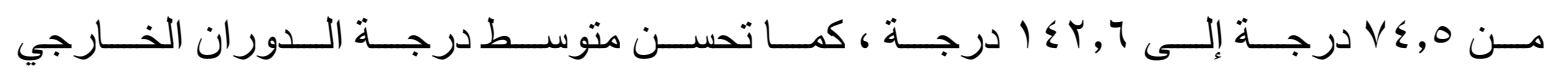

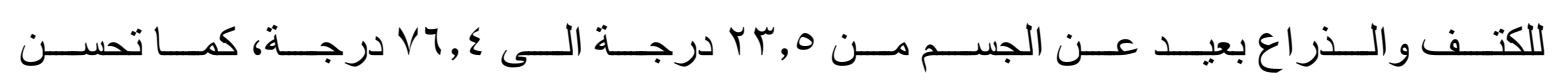

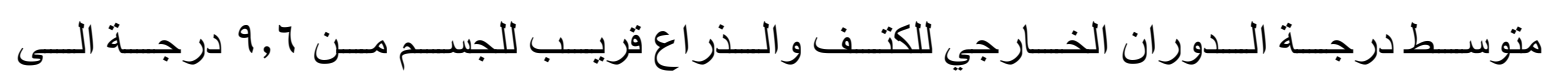

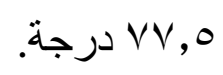

و هــذا يعنـــي أن التحســن فــي مســتوى رفــع الــذر اع و التحســن فـــي الــدوران الخارجي للكتف بعد إجر اء الجر احة ذو دلالة إحصائية جيدة. 
ASSESSMENT OF ACTIVE SHOULDER ROTATION AFTER TENDON... 337

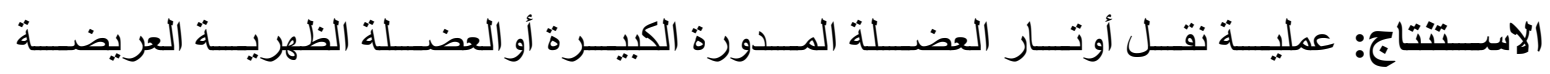

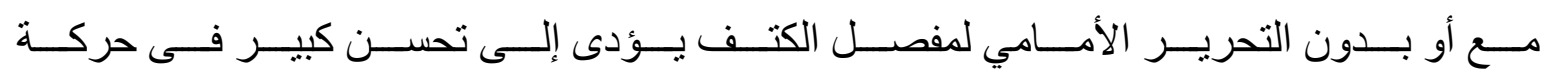

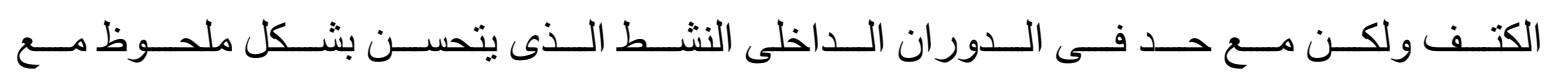
العلاج الطبيعى. 